\title{
GENDER DIFFERENCES IN ORGANIZATIONAL VALUES AMONG RECENT COLLEGE GRADUATES
}

CAROLYN STOUT MORGAN MYRNA L. CARNEY

University of Oklahoma

One of the obstacles to career advancement for women may be the common stereotype that women want different things from work than men do. It has been assumed that women bring to organizations a different set of manners (Hennig and Jardim, 1977) and a different set of wants and expectations (O'Leary, 1974; Schwartz, 1971). Indeed, some studies report gender differences in attitudes toward promotion, new responsibilities, nice people to work with, and good hours (Manhardt, 1972; Crowley et al., 1973; Kanter, 1977; Brenner and Tomkiewicz, 1979), but the explanation for these differences varies.

The learning perspective suggests that the basic ingredients of personality come from early sex role socialization that produces a system in which females and males exhibit different 
personality traits; for example, males are independent and aggressive whereas females are nurturant and emotional (Kohlberg, 1966; Lynn, 1966; Rubin et al., 1974; Bem and Bem, 1976). This supposedly leads to a pattern of femalemale interaction in organizations in which power, leadership, decision making, and control are considered to be male functions, and support and nurturing behaviors are expected of females (Kanter, 1977). Women's socialization for the mother role also means that decisions have to be made about commitment to the labor force and commitment to a family.

Alternative explanations for gender differences in career expectations focus on the structure of opportunity facing women and men. Kanter (1977) and others (Kohn and Schooler, 1973) argue that many aspects of women's aspirations, attitudes, and behaviors in the work place are related more to characteristics of hierarchical organizations than to those of gender or personality. That is, attitudes and behaviors may be more position-linked than sex-linked. In her study of a large corporation, Kanter (1977) observed that men and women had dramatically different opportunities for promotion. Most men were in positions where it was possible to advance their careers; most women were in dead-end jobs. Whereas the men eagerly anticipated promotion, most of the women were much more ambivalent. When the few women in high-ranking jobs were studied, however, their achievement ambitions were found to be no different from those of men. Further support for the argument that structural changes can lead to behavioral changes is the finding by Epstein (1981) that as opportunities were created for women in law, their goals and ambitions changed accordingly.

These perspectives are not mutually exclusive; both can be used to explain gender differences in organizational behavior. Whatever their origin, however, the differences in gender attitudes and behaviors are thought to serve to keep women out of the organizational network of power.

Of interest in this research is the similarity or dissimilarity in the ranking of importance of certain job factors by men 
and women graduates who are entering the work place directly from college. No data are available on the sex role socialization of these graduates. However, we know their response to a question about the proper role of married women. We also have data on their major field of study. Although women today account for a greater proportion of the enrollment in MBA classes and in schools of law and medicine than they did a decade ago, most women still choose gender-traditional majors, as do most men. We might assume that people who choose atypical majors are more "atypical" in their work and sex role attitudes than those who choose gender-typical fields of study. Women in nontraditional academic majors have been found to have higher ACT scores and degree expectations, feel better prepared in math, come from higher family income levels, and view women's roles outside the home as less restrictive than women in traditional fields of study (Carney and Morgan, 1981). Less is known of males in gender-nontraditional majors.

The importance of this study lies in the timing of data collection. We are able to determine the importance college graduates place on such organizational features as promotion, fringe benefits, and job security before the structure of the work place may have influenced their expectations.

\section{DATA AND METHODS}

Data come from a survey of 232 recent college graduates' assessment of their college experiences, their attitudes toward a number of social issues, and their ranking of the importance of certain job factors. ${ }^{1}$ Responses from these males $(\mathrm{N}$ $=134)$ and females $(\mathrm{N}=98)$ will be analyzed by comparing their mean scores (rated from 1 to 3, not important to very important) for 11 job-related characteristics, including high salary, prestige or professional status, fringe benefits, flexible hours, nice people to work with, absence of supervision by others, opportunity for promotion, use of creativity or 
originality, avoidance of work under high pressure, and responsibility. After an analysis of mean response differences by sex, the rating of job factors by males in gendertraditional male majors (architecture, natural sciences, computer science, business, engineering, and physical sciences) will be compared to those of females in those same majors. Likewise, responses from females and males in gendertraditional female majors (education, home economics, languages, fine arts, social sciences, humanities, journalism, and health) will be analyzed. Finally, responses of females in gender-traditional and nontraditional major fields will be examined and the same procedure will be followed for males. A gender-nontraditional major is one in which the student's gender is significantly underrepresented a the degree-granted institution. A gender-traditional major refers to those majors in which the student's gender is overrepresented. Over- and underrepresentation is determined by comparing the malefemale ratio in the graduating student population (57:43) with the male-female ratios in each of the academic major areas. For example, the male-female ratio for engineering graduates is 82:18; therefore, engineering is defined as a maletraditional major and a female-nontraditional major. Past historical data from the degree-granting institution of graduating students show the same disproportionate malefemale ratios by academic major areas; therefore, the data are not unique for the given year.

The statistical procedure chosen for these analyses is analysis of variance (Downie and Heath, 1974).

\section{RESULTS}

A ranking of the importance of the 11 job factors by the group as a whole reveals four factors that cluster together as of high importance: responsibility, nice people to work with, 
TABLE 1

A Comparison of Female and Male Graduating Seniors' Ranking of Job Factors and Response to Sex Role Question

\begin{tabular}{lccc}
\hline & Females & Males & \\
Item & 1.98 & 1.78 & $6.10^{*}$ \\
\hline High salary & 1.86 & 1.71 & 2.63 \\
Prestige or professional status & 1.68 & 1.46 & 2.14 \\
Security & & & \\
$\begin{array}{l}\text { Flexible hours; availability of } \\
\text { part-time work }\end{array}$ & 2.20 & 2.38 & 3.11 \\
Absence of supervision by others & 2.15 & 2.22 & 0.53 \\
$\begin{array}{l}\text { Opportunity for promotion } \\
\text { Fringe benefits }\end{array}$ & 1.42 & 1.28 & $3.62 *$ \\
Nice people to work with & 1.60 & 1.60 & 0.01 \\
Use of creativity or originality & 1.24 & 1.33 & 1.76 \\
Avoidance of work under pressure & 1.37 & 1.32 & 0.47 \\
$\begin{array}{l}\text { Responsibility } \\
\text { The activities of married women } \\
\text { are best confined to the home } \\
\text { and family }\end{array}$ & 2.24 & 2.31 & 0.63 \\
& 1.26 & 1.22 & 0.32 \\
\hline
\end{tabular}

NOTE: $\bar{X}$ on the job factors is based on a ranking of 1 to 3 with $1=$ very important; 2 = important; and $3=$ not important. $\bar{X}$ on the sex role question is based on a scale of 1 to 5 , with $1=$ strongly agree; 2 = agree somewhat; $3=\operatorname{mixed}$ feelings; 4 = disagree somewhat $; 5$ = strongly disagree.

*Significant at .05 with difference of means test.

the opportunity for promotion, and the use of creativity on the job. Somewhat less important are security, fringe benefits, prestige, high salary, absence of supervision, flexible hours, and the avoidance of work under pressure.

Table 1 shows the mean response by sex in the ranking of the 11 job factors, as well as the response to a sex role question. Analysis of variance reveals only two significantly 
statistical differences in job factor ranking by gender: Males were more likely than females to place importance on a high salary and on the opportunity for promotion. Because these are two key ingredients in the traditional breadwinner role, this is not a surprising finding.

Even more homogeneity in job desires is found when male and female graduates in the same major fields are compared (see Table 2). Only one statistically significant difference-the importance of security on the job-was found between females (1.86) and males (1.47) in the masculine majors (F ratio comparison of columns 1 and 3 ). In this instance, females placed less emphasis on security than did males. Females and males who graduated in feminine majors are also very much alike ( $F$ ratio for columns 2 and 4 ).

The highest number of statistically significant differences appear when female and male graduates are compared by major. Women in feminine majors are significantly more likely than women in masculine majors to want job security and to avoid work under high pressures, whereas women in masculine majors are significantly more likely to place importance on the opportunity for promotion. Males who graduated in masculine majors differ from males who finished in feminine majors in the following ways: they are less likely to place importance on flexible hours, to want to avoid work under pressure, and to want the absence of supervision by others (shown in the last two columns in Table 2, F ratio columns 1 and $2 ; 3$ and 4 ).

In addition to the rating of the importance of the job factors, the graduates in this sample responded to the following statement: "The activities of married women are best confined to the home and family." Possible responses included: strongly agree, agree somewhat, mixed feelings, disagree somewhat, and strongly disagree. Table 1 indicates gender differences in mean response, with men significantly more likely than women to agree that a married woman's place is in the home. This difference particularly shows up in Table 2 


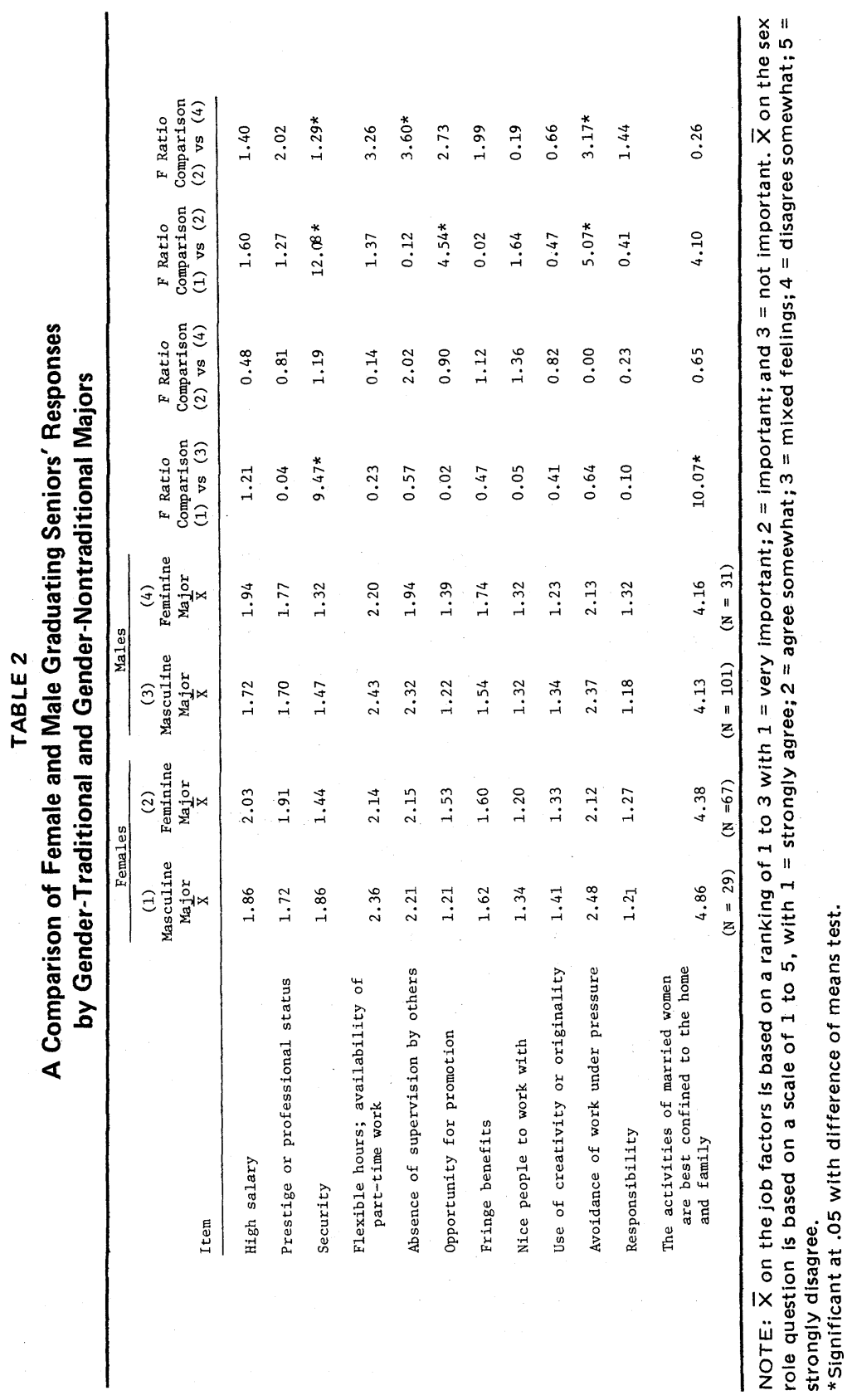


when females and males who graduated in architecture, the natural sciences, computer science, business, engineering, and the physical sciences are compared ( $\mathrm{F}$ ratio, columns 1 and 3). These female graduates are the least likely (of all groupings) to believe that married women's activities are best confined to the home and family $(\bar{X}=4.86)$ whereas their male counterparts are the most likely to agree that married women should be in the home $(\overline{\mathrm{X}}=4.13)$. These men and women are potential colleagues and competitors, which suggests possible conflict. Will women, particularly those who are married, be able to have good relationships with their peers of the opposite sex? What happens if men who believe married women should be in the home become supervisors of married professional women? Although affirmative action policies prohibit the overt discrimination against married women, the persistence of this attitude may operate at the informal level of the organization.

Helen Hacker (1951), in an early article about the minority status of women, predicted that women who occupy nontraditional jobs may experience more difficulties than woman who are employed in traditional occupations. This is the case because woman in nontraditional jobs experience greater marginality; that is, they are caught between the conventional expectations of women's roles and the requirements of the nontraditional jobs. Hacker hypothesized that the woman who is an engineer would suffer more personality problems than the woman who is a librarian. This may still be the case in the 1980s.

\section{DISCUSSION}

As these male and female college graduates leave the university for the work place, they appear to want many of the same things in their jobs. This finding is consistent with recent studies that show a similarity by sex in career aspirations (Rynes and Rosen, 1983) and motivation (Miner, 1974). 
Differences do appear, however, when female graduates in feminine majors are compared with female graduates in masculine majors and when male graduates in masculine majors are compared with males in feminine majors. What females and males consider to be important in the work place, then, seems to be more a function of career field than of gender. What led to the choice of a particular major field of study is still being investigated (Holland, 1973; Gati, 1982), and more research needs to be done in this area.

The findings in this study are based on one institution of higher education in the southwest region of the country; however, these local campus male/female ratios in the gender-traditional and gender-nontraditional majors compare favorably with data published by the National Center for Education Statistics (1979). Studies of graduates from other universities from other regions would be helpful. In any case, our findings suggest that prospective employers would do well to investigate major fields of study as well as job expectations and wants of their applicants.

The females and males in this study who graduated in "atypical" fields of study may encounter more barriers in the work place than their sex-typical peers. There is some suggestion that men in atypical jobs have an easier time than women in atypical jobs (Schreiber, 1979). When information on expectations is lacking, the external status characteristic of gender may be used as a basis for performance expectations. This may work to the advantage of males in atypical occupations but to the disadvantage of females in atypical occupations. For females to have access to power and mobility, they must communicate very clearly their job expectations and desires.

Attention must also be paid to the structure of the work place in the attempt to remove opportunity barriers. Evidence suggests that even if women's socialization had led them to lower their expectations for career advancement, when they are advanced they adjust very well (Kanter, 1977). The continuation of efforts to change policy and practice in regard to 


\title{
the distribution of work opportunity and the sex stereotyping of jobs seems critical to the full utilization of our work force.
}

\begin{abstract}
NOTE
1. This survey was mailed along with a diploma to 635 students completing their bachelor's degree from a large southwestern university in December 1981. Within three months of their graduation 232 questionnaires $(36 \%)$ were returned. Of these, 228 had major codes that could be differentiated as traditional or nontraditional. During the 1981-1982 school year there were 2,307 undergraduates receiving bachelor degrees. Of this total, $45 \%$ were women graduates and $55 \%$ men. Students responding to the survey were 130 men $(57 \%)$ and 98 women $(43 \%)$. Data related to academic majors of the graduating student population indicated that $60 \%$ were masculine majors and $40 \%$ feminine majors, whereas $57 \%$ of the survey sample were masculine and $43 \%$ feminine majors.
\end{abstract}

\section{REFERENCES}

BEM, S. L. and D. J. BEM (1976) "Case study of a nonconscious ideology: training the woman to know her place," pp. 180-190 in S. Cox (ed.) Female Psychology: The Emerging Self. Chicago: Science Research Associates.

BRENNER, O. C. and J. TOMKIEWICZ (1979) "Job orientation of males and females: are sex differences declining?" Personnel Psychology 32: 741-750.

CARNEY, M. and C. S. MORGAN (1981) "Female college persistors: nontraditional versus traditional career fields." J. of College Student Personnel 22: 418-423.

CROWLEY, J. E., T. E. LEVITAN, and R. P. QUINN (1973) "Seven deadly halftruths about women.” Psychology Today 6 (March): 94-97.

DOWNIE, N. M. and R. W. HEATH (1974) Basic Statistical Methods. New York: Harper \& Row.

EPSTEIN, C. F. (1981) Women in Law. New York: Basic.

GATI, I. (1982) "Testing models for the structure of vocational interests." J. of Vocational Behavior 21: 164-182.

HENNING, M. and A. JARDIM (1977) "Women executives in the old-boy network." Psychology Today (January): 76-81.

HACKER, H. (1951) "Women as a minority group." Social Forces 30: 60-69.

HOLLAND, J. L. (1973) Making Vocational Choices: A Theory of Careers. Englewood Cliffs, NJ: Prentice-Hall.

KANTER, R. M. (1977) Men and Women of the Corporation. New York: Basic. 
KOHLBERG, L. (1966) “A cognitive-developmental analysis of children's sex role concepts and attitudes," pp. 82-173 in E. E. Maccoby (ed.) The Development of Sex Differences. Stanford, CA: Stanford Univ. Press.

KOHN, M. and C. SCHOOLER (1973) "Occupational experience and psychological functioning: an assessment of reciprocal effects." Amer. Soc. Rev. 38: 97-118.

LYNN, D. B. (1966) "The process of learning parental and sex role identification." J. of Marriage and the Family 38: 466-470.

MANHARDT, P. J. (1972) "Job orientation of male and female college graduates in business." Personnel Psychology 25: 361-368.

MINER, J. B. (1974) "Motivation to manage among women: studies of business managers and educational administrators." J. of Vocational Behavior 5: 197-208.

National Center for Education Statistics (1979) "Fact-file." The Chronicle of Higher Education.

O'LEARY, V. E. (1974) "Some attitudinal barriers to occupational aspirations in women." Psych. Bull. 31: 809-826.

RUBIN, J. A., F. J. PROVENZANO, and Z. LURIA (1974) "The eye of the beholder: parents' views on sex of newborns." Amer. J. of Orthopsychiatry 44: 512-519.

RYNES, S. and B. ROSEN (1983) "A comparison of male and female reactions to career advancement opportunities." J. of Vocational Behavior 22: 105-116.

SCHREIBER, C. T. (1979) Changing Places: Men and Women in Transitional Occupations. Cambridge: Massachusetts Institute of Technology.

SCHWARTZ, E. B. (1971) The sex Barrier in Business. Atlanta: Georgia State University.

Carolyn Stout Morgan is an Assistant Professor of Sociology and Women's Studies at the University of Oklahoma. She has research interests in a variety of areas including sex role attitudes, variations in fertility patterns, and the role of women in higher education. Recent publications include "Interstate Variations in Teenage Fertility" in Population Research and Policy Review, "An Analysis of Factors Affecting Traditional Family Expectations and Perceptions of Ideal Fertility" in Sex Roles (with Wilbur J. Scott), and "Predicting Sex Role Attitudes" in Social Psychology Quarterly (with Alexis J. Walker).

Myrna L. Carney, Ph.D., is Director of the Center for Instructional Research, The University of Oklahoma. Her research interests are academic performance studies, retention studies, and changes in student attitudes. She is coauthor with Carolyn Stout Morgan on "Female College Persistors: Nontraditional Versus Traditional Career Fields"' in the Journal of College Student Personnel. 